\title{
Brief Communication: Rapid mapping of landslide events: the 3 December 2013 Montescaglioso landslide, Italy
}

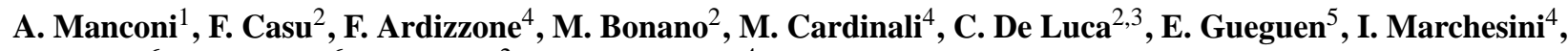 \\ M. Parise ${ }^{6}$, C. Vennari $^{6}$, R. Lanari ${ }^{2}$, and F. Guzzetti ${ }^{4}$ \\ ${ }^{1}$ CNR IRPI, Strada delle Cacce 73, 10135 Turin, Italy \\ ${ }^{2}$ CNR IREA, Via Diocleziano 328, 80124 Naples, Italy \\ ${ }^{3}$ Università degli Studi di Napoli Federico II, Via Claudio 21, 80124 Naples, Italy \\ ${ }^{4}$ CNR IRPI, Via della Madonna Alta 126, 06128 Perugia, Italy \\ ${ }^{5}$ CNR IMAA, C.da Santa Loja, Tito Scalo, 85050 Potenza, Italy \\ ${ }^{6}$ CNR IRPI, Via Amendola, 122/I, 70126 Bari, Italy
}

Correspondence to: A. Manconi (andrea.manconi@irpi.cnr.it)

Received: 31 January 2014 - Published in Nat. Hazards Earth Syst. Sci. Discuss.: 14 February 2014

Revised: - - Accepted: 19 June 2014 - Published: 25 July 2014

\begin{abstract}
We present an approach to measure 3-D surface deformations caused by large, rapid-moving landslides using the amplitude information of high-resolution, X-band synthetic aperture radar (SAR) images. We exploit SAR data captured by the COSMO-SkyMed satellites to measure the deformation produced by the 3 December 2013 Montescaglioso landslide, southern Italy. The deformation produced by the deep-seated landslide exceeded $10 \mathrm{~m}$ and caused the disruption of a main road, a few homes and commercial buildings. The results open up the possibility of obtaining 3-D surface deformation maps shortly after the occurrence of large, rapid-moving landslides using high-resolution SAR data.
\end{abstract}

\section{Introduction}

Large landslides occur in several regions of the earth, causing damage and casualties (Petley, 2012). In places, these phenomena affect urban areas, buildings, roads and rails, threatening the population and causing emergency situations. In such scenarios, rapid mapping of the location and extent of the surface deformation caused by large landslides can provide important indications of the rapid response of civil protection authorities, for rescue and recovery operations and to design and deploy effective monitoring systems (Giordan et al., 2013). Most commonly, post-event landslide maps are compiled through field mapping and/or the visual analysis of aerial photographs taken shortly after a landslide event (Guzzetti et al., 2012). Where the ground displacements are of the order of several metres, and the velocity of the failure is rapid to very rapid (Cruden and Varnes, 1996), access to the landslide area may be difficult or impossible, or too dangerous to perform field mapping. In these circumstances, remote sensing techniques provide an effective alternative to perform semi-quantitative or quantitative assessments of the extent and the amount of the ground deformations (Singleton et al., 2014, and references therein).

Among several remote sensing techniques, space-borne synthetic aperture radar (SAR) has demonstrated its efficiency to monitor changes on the earth's surface produced by natural and human-induced processes (Rott, 2009). In particular, differential SAR interferometry (DInSAR) allows measuring ground deformation by analysing the phase difference between two SAR images (Massonnet et al., 1993) acquired over the same area at different times and from different orbital positions (hereafter referred to as temporal and spatial baselines, respectively). The main advantage of DInSAR is the possibility of measuring sub-centimetre surface displacements over large areas $\left(10^{2}-10^{5} \mathrm{~km}^{2}\right)$. For studying landslides, the application of DInSAR techniques can be limited locally by the unsuitable exposure of the unstable slopes with respect to the satellite acquisition geometry and by large and/or rapid displacements, which may overcome 
the maximum detectable surface velocities between consecutive SAR acquisitions (Wasowski and Bovenga, 2014). In the latter case, interferometric phase information may be affected by high fringe rates leading to processing difficulties in the phase unwrapping step and/or to coherence loss due to misregistration errors (Casu et al., 2011). If the deformation introduces geometric distortions without significantly affecting the SAR image reflectivity, displacements can be observed in the amplitudes of the SAR image pairs acquired before and after the event, with a method hereinafter referred to as "pixel offset" (PO).

Compared with standard DInSAR, the PO approach applied to SAR imagery provides 2-D displacement information, i.e. the displacement components across and along the satellite's track (range and azimuth direction, respectively). Ground displacements that can be detected using the PO approach are around $1 / 10$ to $1 / 20$ of the pixel size, which for modern SAR sensors is in general of the order of a few metres. The PO approach provides an additional and complementary tool to analyse and interpret surface deformations in areas where standard DInSAR techniques are hindered by geometrical or morphological constraints (e.g. Manconi and Casu, 2012). Although the PO approach is becoming popular to monitor ground displacements in unstable slopes (Gance et al., 2014), the approach has been so far rarely applied to landslide event scenarios, and in general the majority of the studies have considered optical imagery (Singleton et al., 2014, and references therein).

In this work, we present the first results of a rapid mapping effort conducted during a recent landslide emergency that occurred in 3 December 2013 in the Montescaglioso municipality, Basilicata, southern Italy (Fig. 1). In the following, we first describe the main features of the landslide event. We then present qualitative and semi-quantitative information obtained immediately after the event using consolidated mapping approaches (Guzzetti et al., 2012). Next, we show the surface deformation map obtained using the PO technique applied to high-resolution SAR images acquired by the COSMO-SkyMed (CSK) satellites before and after the landslide event. PO analyses of SAR images captured along ascending and descending orbits allowed the retrieval of the full three-dimensional deformation field caused by the landslide (Raucoules et al., 2013; Hu et al., 2014).

\section{Local setting}

A large landslide struck the SW slope of Montescaglioso, a town located in the Matera Province, southern Italy, on 3 December 2013, after $56 \mathrm{~h}$ of continuous rainfall (Fig. 1). As many other towns in southern Italy, Montescaglioso was built at the top of a hill bounded by steep slopes affected by multiple landslides of different types (Cruden and Varnes, 1996). In particular, the slope affected by the new landslide is characterized by large, deep-seated, ancient slope fail- ures (Boenzi et al., 1971). Annual rainfall in the area averages $570 \mathrm{~mm}$, with most of the rainfall falling in November $(187 \mathrm{~mm})$. In the general area, the crop-out sediments of the "Bradanic trough", Pleistocene in age (Tropeano et al., 2002), included a regression (coarsening upward) sequence made up of clay (at the bottom), sand and gravel (at the top). In the slope affected by the new Montescaglioso landslide, sediments are heterogeneous, as demonstrated by the presence of large blocks of conglomerates (with a maximum size of about $5 \mathrm{~m} \times 3 \mathrm{~m}$ ) found at different elevations in the slope. We attribute the chaotic distribution of the materials to repeated, old and very old landslides - the result of a complex morphological evolution of the area.

\section{The new Montescaglioso landslide}

Between 5 and 8 October 2013, the general area between Apulia and Basilicata, including the town of Montescaglioso, was struck by a severe rainfall event with cumulated rainfall $E=246 \mathrm{~mm}$ and mean rainfall intensity $I=3.6 \mathrm{~mm} \mathrm{~h}^{-1}$. The regional rainfall event caused widespread flooding, numerous shallow landslides, severe economic losses, and four fatalities. A second rainfall event hit the Montescaglioso area in the period from 30 November, 14:00 CET, to 2 December, 22:00 CET, with a cumulated rainfall measured at the Ginosa rain gauge, $8 \mathrm{~km}$ from Montescaglioso, of $E=151.6 \mathrm{~mm}$ and mean rainfall intensity $I=2.7 \mathrm{~mm} \mathrm{~h}^{-1}$. The two events exceeded $70 \%$ of the mean annual precipitation.

The length of the landslide measured along the main displacement axis is $L_{\mathrm{L}} \sim 1.2 \times 10^{3} \mathrm{~m}$, and the width measured perpendicularly to the main axis is $W_{\mathrm{L}} \sim 8.0 \times 10^{2} \mathrm{~m}$, for a total landslide area of $A_{\mathrm{L}} \sim 3.0 \times 10^{5} \mathrm{~m}^{2}$. The deepseated slope failure occurred along a SSW-facing slope and extended from $\sim 200 \mathrm{~m}$ of elevation in the source area to $\sim 110 \mathrm{~m}$ of elevation at the toe, with an average terrain gradient of $\sim 10 \%$. Movement of the landslide damaged or destroyed more than $500 \mathrm{~m}$ of the main road connecting the town of Montescaglioso to the Province Road SP175. The large failure involved a few warehouses, a supermarket, and private homes located on the right bank of a channel in the area known as "Cinque Bocche" (Fig. 1). Anecdotal information collected immediately after the event reveals that the landslide was rapid (Cruden and Varnes, 1996), with the main movement occurring in a short period of 15-20 min, corresponding to an estimated average velocity of about $0.5-$ $1 \mathrm{~m} \mathrm{~min}^{-1}$. The movement started at 13:05 CET and affected the road shortly afterward. Next, the movement involved the lower-left flank of the landslide, resulting in the formation of a swarm of scarps and counter-scarps, several tens of metres in length and with a maximum height of 7-8 $\mathrm{m}$. A house (shown by "C" in Fig. 1) was moved a few metres downslope and tilted. Fortunately, the building did not collapse and allowed the inhabitants to escape avoiding direct consequences. 


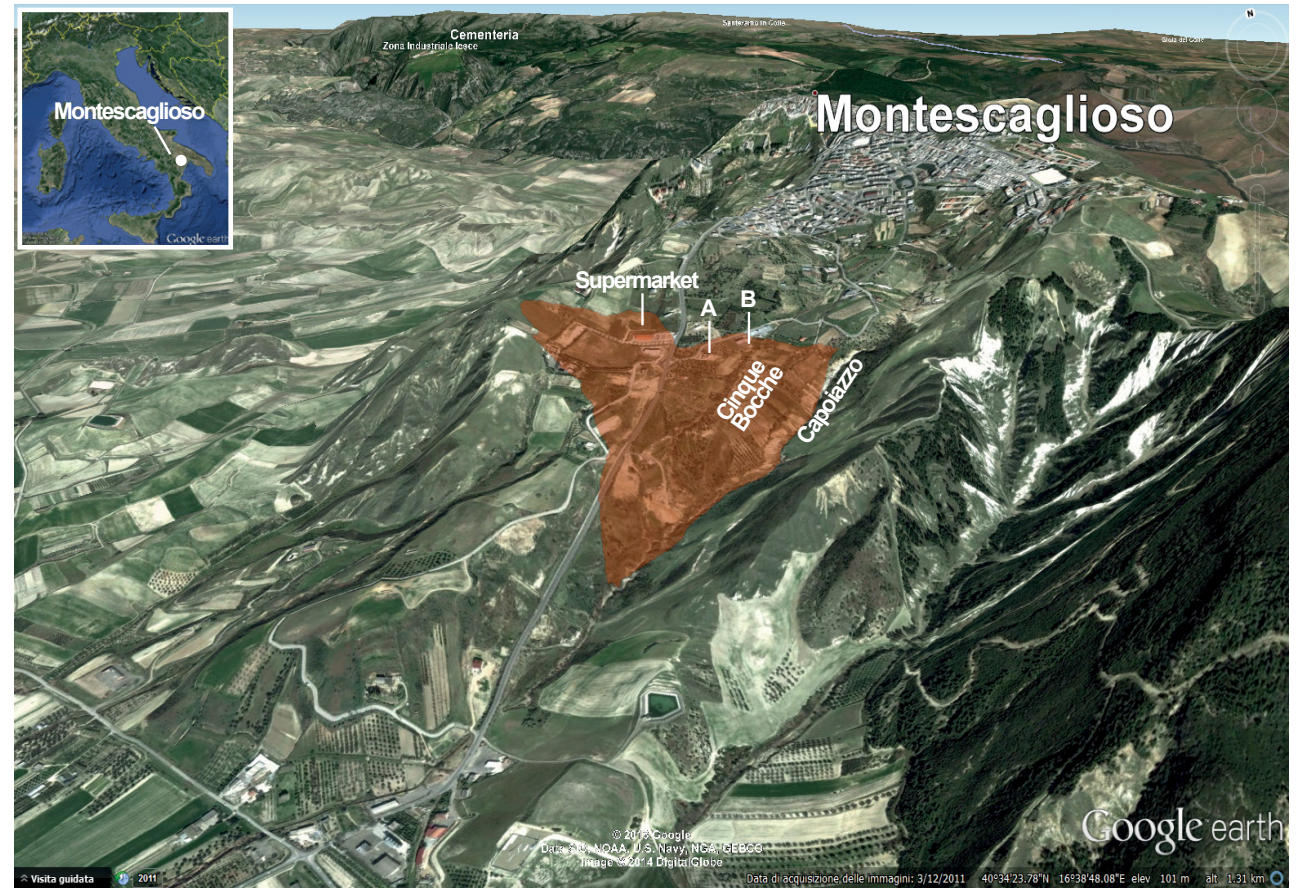

Figure 1. Montescaglioso, southern Italy. The red area shows the area affected by the 3 December 2013 Montescaglioso landslide. Locations of a supermarket (A) and of most damaged buildings (B and $\mathbf{C})$ are shown. (D) and (E) show locations of the Cinque Bocche and Capoiazzo channels. Source of terrain map: Google Earth ${ }^{\mathrm{TM}}$.

\section{Geomorphological mapping of the new Montescaglioso landslide}

To respond to a request of the Italian National Department for Civil Protection (DPC), in the period from 9 to 24 December 2013, immediately after the landslide, we conducted an initial geomorphological analysis to prepare a preliminary landslide inventory map and to characterize the new Montescaglioso landslide in the context of the pre-existing landslides in the study area. This was done through the visual interpretation of seven sets of 30 black-and-white stereoscopic aerial photographs taken from 1947 to 2003, at scales ranging from $1: 24000$ to $1: 36000$ (Table S1 in the Supplement). The aerial photographs were obtained as images in JPEG format at low resolution ( $88 \mathrm{dpi}$ of the negative) from the online catalogue of aerial photographs of the Istituto Geografico Militare Italiano (IGMI, http://www.igmi.org/voli/). The images were printed and visually analysed using a mirror "double vision" stereoscope with image magnifications ranging from $1.5 \times$ to $15 \times$. Despite the low resolution of the aerial photographs, visual inspection allowed the identification and mapping of a large number of geomorphological features related to the presence of pre-existing mass movements in the area. A set of photographical characteristics and morphological features were examined on the stereoscopic aerial photographs, including shape, size, photographic colour, tone, mottling, texture, pattern of objects, site topography, and setting (Guzzetti et al., 2012). The geomorphological features were drawn on transparent plastic sheets placed over the aerial photographs and then digitized exploiting GIS software and a 2006 digital orthophotomap available through a Web Map Service provided by the Italian Environmental Ministry (http://www.pcn.minambiente.it).

The geomorphological landslide map shows the following (Fig. S2 in the Supplement): (i) a large, very old landslide, largely dismantled by erosion processes, including other landslides, that affected the entire slope; (ii) a number of smaller and more recent landslides, mainly translational slides and flows, which are distributed within and at the edges of the pre-existing, very old landslide; and (iii) numerous, mostly minor, landslide escarpments. Inside the preexisting, very old landslide we recognized different generations of landslides. Some of these landslides affect the town of Montescaglioso (Fig. S2 in the Supplement).

In addition to the interpretation of the stereoscopic aerial photographs, we performed field surveys to evaluate the main consequences of the landslide and to compile a map of the surface deformations in the landslide area, aimed at identifying zones within the landslide mass that showed different kinematics (Parise, 2003, and references therein). The field surveys were aided by the visual analysis of post-event terrestrial photographs and photographs taken during helicopter flights (see Figs. S3 and S4 in the Supplement). The geomorphological features mapped in the field and through the inspection of the terrestrial and the helicopter photographs 
included single fractures, sets of fractures, tension cracks, trenches up to $6 \mathrm{~m}$ in depth or width, and pressure ridges. Many of the geomorphological features mapped immediately after the landslide event were later destroyed by the construction of temporary roads.

\section{Three-dimensional surface deformation from space-borne SAR}

The Italian Space Agency (ASI) made available a set of Xband CSK images for the study area. The data set consists of 31 images taken along ascending orbits in the period from 30 January 2012 to 18 December 2013 and 12 images taken along descending orbits in the period from 21 March 2012 to 12 December 2013. Both sub-sets included a post-event image.

First, we performed a conventional DInSAR analysis exploiting acquisitions taken across the investigated event, suing the approach proposed by Massonet et al. (1993). In addition, we carried out spectral shift compensation and interferometric fringes filtering (Bürgmann et al., 2000). However, in the area affected by the new Montescaglioso landslide the conventional DInSAR processing produced unsatisfactory results, which were primarily attributed to the excessive fringe noise related to the fast-moving deformation pattern of the landslide (Fig. S5 in the Supplement). We note that the retrieved DInSAR signal is generally very noisy also in areas located near (but outside of) the new Montescaglioso landslide. We consider this a consequence of the large temporal and/or spatial baselines that characterize the available CSK image pairs across the landslide event and, in general, the entire data distribution (Fig. S6 in the Supplement).

Considering the poor quality of the DInSAR results, we applied the amplitude-based, pixel-offset technique to the SAR data pairs across the event with the smallest spatial baselines, to reduce the impact of the spatial decorrelation. In particular, we considered the ascending 16 January 201318 December 2013 and the descending 10 January 201312 December 2013 data pairs, characterized by spatial baselines of 155 and $40 \mathrm{~m}$, respectively, covering approximately the same time interval ( 336 and 332 days, respectively). For these data pairs, we exploited AMPCOR, a Fortran routine based on the normalized cross-correlation approach, available in the ROI_PAC software (Rosen et al., 2004). We considered a matching window of $64 \times 64$ pixels and calculated the PO considering a sparse grid with an undersampling factor of 4 pixels. We applied a spatial smoothing filter to reduce high-frequency noise. Readers interested in the details of the PO processing used here are referred to Casu et al. (2011).

As mentioned already, the PO technique allows identifying with a good spatial resolution areas affected by large displacements, which are of the order of or exceed the pixel size (e.g. $3 \mathrm{~m}$ for the available CSK data). Combining the PO measurements obtained exploiting the CSK ascending and descending orbits, we determined the three-dimensional deformation pattern caused by the new Montescaglioso landslide (Fig. 2). Visual inspection of Fig. 2 reveals that the ground displacements have a dominant SSW component, with values exceeding $10 \mathrm{~m}$ for large parts of the landslide deposit, and exceeding locally $20 \mathrm{~m}$. Significant subsidence values were identified in the areas experiencing the largest damages, whereas a distinct uplift of up to $5 \mathrm{~m}$ was detected close to the accumulation area.

\section{Discussion and conclusions}

The exploitation of remote sensing data and technologies for the rapid mapping of natural and/or human-induced disasters is becoming a standard practice to support civil protection emergency and recovery operations (Boccardo, 2013). This includes analyses of data acquired from different remote platforms (e.g. ground-based systems, manned and unmanned aerial systems, space-borne systems) and exploiting different types of sensors (e.g. panchromatic, multispectral, hyperspectral, thermal, LiDAR, radar). For large landslides, selection of the most appropriate mapping and monitoring technique depends on multiple factors (Wieczorek and Snyder, 2009; Giordan et al., 2013). After a new landslide event, rapid evaluation of the area affected by the mass wasting and measurements of the associated surface deformations are of primary interest to design and deploy effective monitoring networks and to support early warning systems. Post-event deformation maps can also contribute to improved geomorphological analyses and geophysical investigations and prove useful for the evaluation of the residual risk and, for the selection, the design, and the implementation of mitigation and stabilization measures (Revellino et al., 2010).

Most commonly, optical images captured by aerial and satellite sensors before and after a landslide event are used for first-order evaluations of ground displacements in emergency scenarios. However, optical data can only provide qualitative and/or semi-quantitative bi-dimensional information, and the possibility of obtaining optical data of sufficient quality depends on local meteorological conditions. Frequently, during and immediately following the occurrence of rainfall-induced landslides, cloud coverage limits the visibility of a landslide area. Airborne LiDAR represents an additional remote sensing tool to detect and map post-event landslide deformation and to estimate the volume of the displaced mass (e.g. Giordan et al., 2013). However, the acquisition of LiDAR data can be limited by multiple operational constraints, including the local meteorological conditions, and the costs of the surveys.

Where the setting of the local terrain is suitable for the satellite acquisition geometry (Colesanti and Wasowski, 2006), space-borne SAR is a valid alternative to detecting, mapping and measuring surface deformations caused by active landslides. SAR data can be captured in all weather 

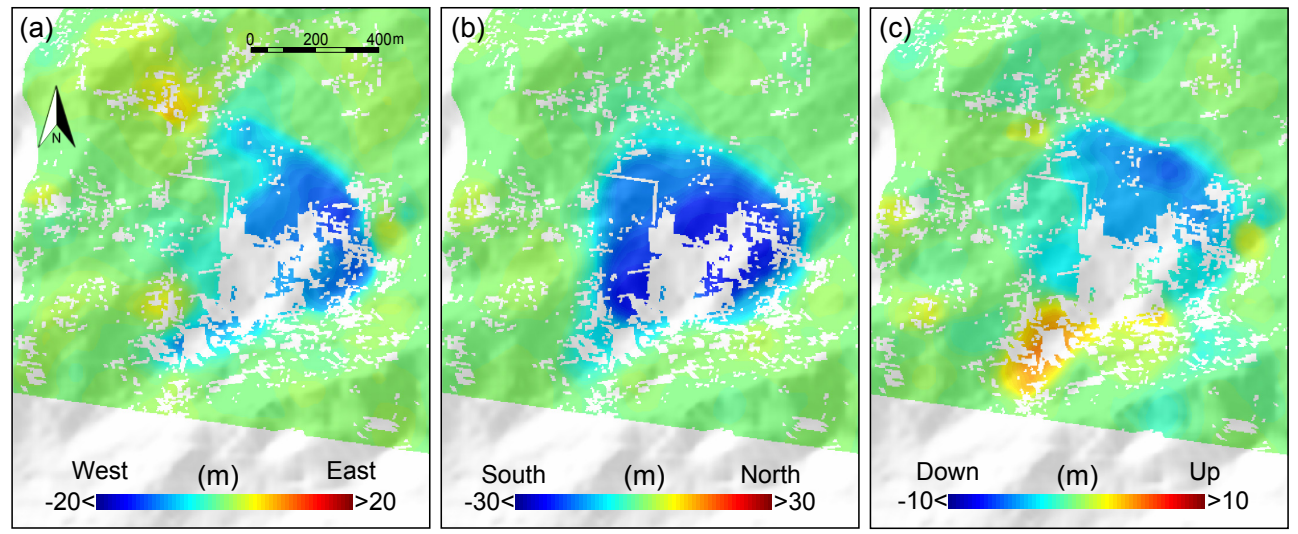

Figure 2. The new Montescaglioso landslide of 3 December 2013. Pixel-offset results for the (a) east-west, (b) north-south, and (c) updown components of the surface deformation. Measurements are the results of the combination of pixel-offset results obtained processing COSMO-SkyMed images acquired along ascending and descending orbits.

conditions, during the day and the night, with a significant advantage over other remote sensing techniques, and chiefly the techniques based on optical (multispectral) data. Although conventional DInSAR techniques have known limitations for detecting and measuring the deformation of rapidmoving landslides, García-Davalillo et al. (2014) have shown recently that processing of L-Band SAR imagery was capable of detecting and measuring landslide surface velocities up to $1 \mathrm{~m}$ per year.

We have shown that the amplitude information captured by space-borne SAR images can be exploited to detect, map, and measure deformations caused by large, rapid-moving landslides. For the purpose, we exploited the "pixel offset" (PO) technique (Rosen et al., 2004) using pairs of SAR image acquired before and after the new Montescaglioso landslide by the CSK satellites, which ensures high spatial resolution $(3 \mathrm{~m} \times 3 \mathrm{~m})$ and short revisit times (16 days on average for the available data sets). We combined the PO results obtained from ascending and descending orbits to retrieve the three-dimensional geometry of the ground displacements. To our knowledge, this is the first time that this approach was applied to the rapid mapping of the 3-D surface displacement of rapid-moving landslides. The application of the PO technique to obtain a rapid assessment of the surface displacements after an event depends on two main factors: (i) the availability of SAR imagery, which is constrained by the satellite configuration and predefined acquisition plan, and (ii) the PO processing time. For the Montescaglioso landslide case study, the CSK imagery was made available to us 8 and 15 days after the landslide event, for the descending and the ascending orbits, respectively. To obtain this result, the CSK acquisition plan was modified specifically to contribute to the Montescaglioso civil protection emergency scenario. The 3-D deformation maps computed exploiting the PO technique were delivered to the civil protection authorities less than $24 \mathrm{~h}$ after receiving the SAR imagery. Depending on the area of interest and the acquisition plan, the CSK configuration may provide SAR images with shorter revisit times. In principle, PO results can be produced and delivered just a few days after a landslide event.

The combination of rapid geomorphological mapping, rapid field mapping, and rapid measurements of 3-D deformation proved crucial to supporting civil protection authorities during the emergency following the new Montescaglioso landslide. The results of the geomorphological multi-temporal analysis allowed recognizing the presence of pre-exiting landslides of different size, shape, and relative age that affect larger areas than those identified in existing official maps and reports. The field mapping performed shortly after the event allowed obtaining useful information to better understand the kinematics of the new landslide and for the reconstruction of the geometry of the slip surface (Parise, 2003). Two major landslide scarps were identified in the area. A first scarp, located in the middle of slope in the area where the supermarket was located, formed during the initial phase of movement. A second scarp, located closer to the divide, was generated presumably during a second phase of movement, as a result of the retrogressive evolution of the landslide. The 3-D ground deformation measurements obtained through the PO analysis detected two main directions of movement associated with (Fig. 3) (i) the main landslide event (SSW) and (ii) a secondary and smaller event (SSE). Thus, the PO results are in agreement with the magnitude and the deformation mechanisms recognized and mapped in the field. The combined interpretation of the results obtained with classical and new methods presented in this work was essential for the design of the topographic monitoring network installed in the Montescaglioso area. We expect the results obtained to be useful for the selection and the design of the mitigation strategies that will be implemented in the landslide area and in the neighbouring regions. 


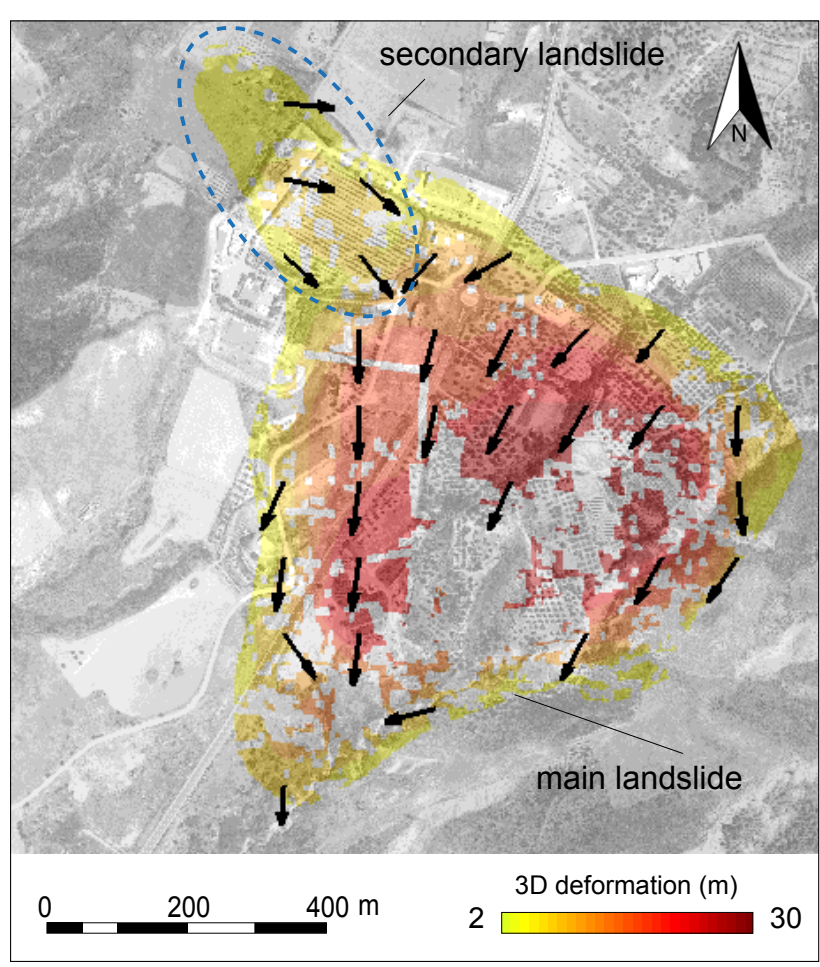

Figure 3. The new Montescaglioso landslide of 3 December 2013. Map of the surface deformation obtained through the pixel-offset (PO) analysis prepared using the ${ }^{{ }^{3}}$ 3DA approach (Allasia et al., 2013). Colours show magnitude of the 3-D deformation field. Arrows show direction of movement (unit vectors) derived from the $\mathrm{PO}$ analysis in the E-W and N-S plane. Deformations smaller than $2 \mathrm{~m}$ are not shown. The deformation field shows two main directions of motion: (i) a dominant SSW direction caused by the main landslide and (ii) a secondary SSE direction caused by a parasitic landslide, encompassed by the dashed blue ellipse.

Finally, we note that future integrations of information obtained exploiting classical geomorphological analyses and SAR images, through DInSAR and/or PO techniques, might open up new scenarios for the analysis of rapid-moving landslides characterized by complex spatial and/or temporal heterogeneities of the deformation field. We expect that the increasing availability of space-borne, high spatial and/or temporal resolution SAR images, such as COSMO-SkyMed and TerraSAR-X, and the forthcoming ALOS PALSAR-2 and Sentinel missions, will enhance the possibility of performing the rapid mapping of large landslides in complex emergency scenarios and of supporting civil protection authorities in the aftermath of catastrophic landslide events.
Acknowledgements. The research leading to these results has received funding from the European Union Seventh Framework Programme (FP7/2007-2013) under grant agreement no. 312384 (http://www.lampre-project.eu/) and from the Italian National Department of Civil Protection (DPC). We are grateful to L. Candela of the Italian Space Agency (ASI) for making available the COSMO-SkyMed images used in this study. We thank the editor Bruce Malamud and two anonymous reviewers for comments and suggestions.

Edited by: R. Lasaponara

Reviewed by: two anonymous referees

\section{References}

Allasia, P., Manconi, A., Giordan, D., Baldo, M., and Lollino, G.: ADVICE: A New Approach for Near-Real-Time Monitoring of Surface Displacements in Landslide Hazard Scenarios, Sensors, 13, 8285-8302, doi:10.3390/s130708285, 2013.

Boccardo, P.: New perspectives in emergency mapping, Eur. J. Remote Sens., 571-582, doi:10.5721/EuJRS20134633, 2013.

Boenzi, F., Radina, B., Ricchetti, G., and Valduga, A.: Note illustrative della Carta Geologica d'Italia alla scala 1:100.000, Foglio 201 Matera, Serv. Geol. It., 48 pp., 1971.

Bürgmann, R., Rosen, P. A., and Fielding, E. J.: Synthetic Aperture Radar Interferometry to Measure Earth's Surface Topography and Its Deformation, Annu. Rev. Earth Planet. Sci., 28, 169209, doi:10.1146/annurev.earth.28.1.169, 2000.

Casu, F., Manconi, A., Pepe, A., and Lanari, R.: Deformation Time-Series Generation in Areas Characterized by Large Displacement Dynamics: The SAR Amplitude Pixel-Offset SBAS Technique, IEEE Trans. Geosci. Remote Sens., 49, 2752-2763, doi:10.1109/TGRS.2010.2104325, 2011.

Colesanti, C. and Wasowski, J.: Investigating landslides with spaceborne Synthetic Aperture Radar (SAR) interferometry, Eng Geol., 88, 173-199, doi:10.1016/j.enggeo.2006.09.013, 2006.

Cruden, D. M. and Varnes, D. J.: Landslides Types and Processes, in: Landslides: Investigation and Mitigation, edited by: Turner, A. K. and Schuster, R. L., 36-75, National Academy Press, WA, 1996.

Gance, J., Malet, J.-P., Dewez, T., and Travelletti, J.: Target Detection and Tracking of moving objects for characterizing landslide displacements from time-lapse terrestrial optical images, Eng. Geol., 172, 26-40, doi:10.1016/j.enggeo.2014.01.003, 2014.

García-Davalillo, J. C., Herrera, G., Notti, D., Strozzi, T., and Álvarez-Fernández, I.: DInSAR analysis of ALOS PALSAR images for the assessment of very slow landslides: the Tena Valley case study, Landslides, 11, 225-246, doi:10.1007/s10346-0120379-8, 2014.

Giordan, D., Allasia, P., Manconi, A., Baldo, M., Santangelo, M., Cardinali, M., Corazza, A., Albanese, V., Lollino, G., and Guzzetti, F.: Morphological and kinematic evolution of a large earthflow: The Montaguto landslide, southern Italy, Geomorphology, 187, 61-79, doi:10.1016/j.geomorph.2012.12.035, 2013. 
Guzzetti, F., Mondini, A. C., Cardinali, M., Fiorucci, F., Santangelo, M., and Chang, K.-T.: Landslide inventory maps: New tools for an old problem, Earth Sci. Rev., 112, 42-66, doi:10.1016/j.earscirev.2012.02.001, 2012.

Hu, J., Li, Z. W., Ding, X. L., Zhu, J. J., Zhang, L., and Sun, Q.: Resolving three-dimensional surface displacements from InSAR measurements: A review, Earth-Sci. Rev., 133, 1-17, doi:10.1016/j.earscirev.2014.02.005, 2014.

Manconi, A. and Casu, F.: Joint analysis of displacement time series retrieved from SAR phase and amplitude: Impact on the estimation of volcanic source parameters, Geophys. Res. Lett., 39, L14301, doi:10.1029/2012GL052202, 2012.

Massonnet, D., Rossi, M., Carmona, C., Adragna, F., Peltzer, G., Feigl, K., and Rabaute, T.: The displacement field of the Landers earthquake mapped by radar interferometry, Nature, 364, 138142, doi:10.1038/364138a0, 1993.

Parise, M.: Observation of surface features on an active landslide, and implications for understanding its history of movement, Nat. Hazards Earth Syst. Sci., 3, 569-580, doi:10.5194/nhess-3-5692003, 2003.

Petley, D.: Global patterns of loss of life from landslides, Geology, 40, 927-930, doi:10.1130/G33217.1, 2012.

Raucoules, D., de Michele, M., Malet, J.-P., and Ulrich, P.: Timevariable 3-D ground displacements from high-resolution synthetic aperture radar (SAR). Application to La Valette landslide (South French Alps), Remote Sens. Environ., 139, 198-204, doi:10.1016/j.rse.2013.08.006, 2013.
Revellino, P., Grelle, G., Donnarumma, A., and Guadagno, F. M.: Structurally controlled earth flows of the Benevento province (Southern Italy), Bull. Eng. Geol. Environ., 69, 487-500, doi:10.1007/s10064-010-0288-9, 2010.

Rosen, P. A., Hensley, S., Peltzer, G., and Simons, M.: Updated repeat orbit interferometry package released, Eos Trans. Am. Geophys. Union, 85, 47-47, doi:10.1029/2004EO050004, 2004.

Rott, H.: Advances in interferometric synthetic aperture radar (InSAR) in earth system science, Prog. Phys. Geogr., 33, 769-791, doi:10.1177/0309133309350263, 2009.

Singleton, A., Li, Z., Hoey, T., and Muller, J.-P.: Evaluating subpixel offset techniques as an alternative to D-InSAR for monitoring episodic landslide movements in vegetated terrain, Remote Sens. Environ., 147, 133-144, doi:10.1016/j.rse.2014.03.003, 2014.

Tropeano, M., Sabato, L., and Pieri, P.: Filling and cannibalization of a foredeep: the Bradanic Trough, Southern Italy, Geol. Soc. Lond. Spec. Publ., 191, 55-79, doi:10.1144/GSL.SP.2002.191.01.05, 2002.

Wasowski, J. and Bovenga, F.: Investigating landslides and unstable slopes with satellite Multi Temporal Interferometry: Current issues and future perspectives, Eng. Geol., 174, 103-138, doi:10.1016/j.enggeo.2014.03.003, 2014.

Wieczorek, G. F. and Snyder, J. B.: Monitoring slope movements, Geol. Monit., 245-271, 2009. 